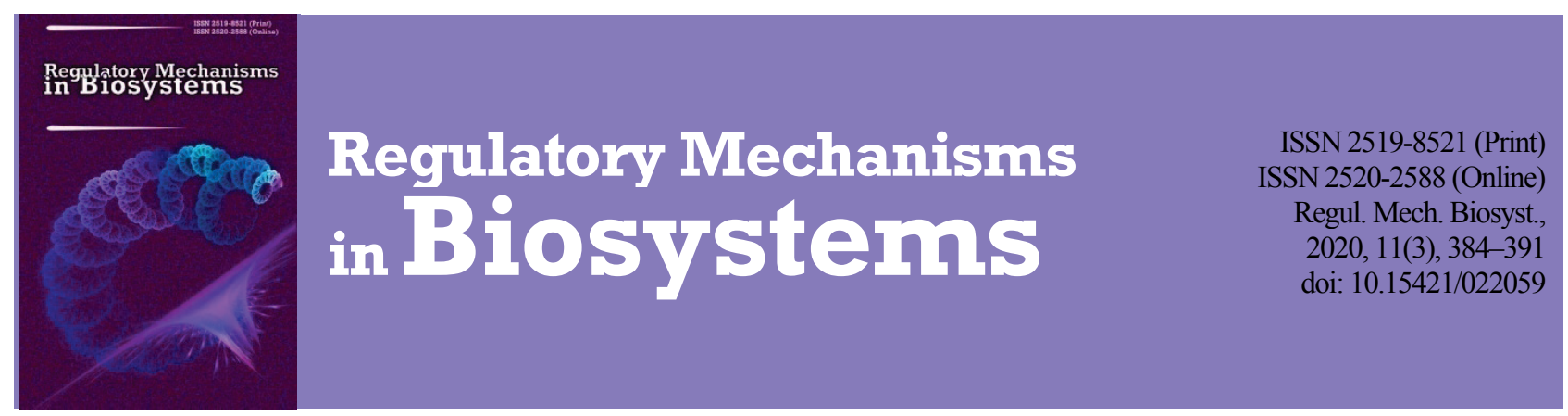

\title{
Influence of melatonin on the kidneys of rats with experimental diabetes mellitus type 2
}

\author{
A. V. Semenko* , Y. V. Murdasov*\#, S. V. Kirichenko*, V. I. Zhyliuk**, G. A. Ushakova* \\ *Oles Honchar Dnipro National University, Dnipro, Ukraine \\ **Dnipropetrovsk Medical Academy of the Ministry of Health of Ukraine, Dnipro, Ukraine
}

Article info

Received 04.07.2020

Received in revised form 20.08.2020

Accepted 22.08.2020

Oles Honchar Dnipro National University,

Gagarin ave., 72,

Dnipro, 49010, Ukraine.

Tel.: + 38-067-632-36-13

E-mail:

ushakova_g@ukr.net

Dnipropetrovsk Medical Academy of the Ministry of Health of Ukraine,

Vernadskyst., 9

Dnipro, 49044, Ukraine.

Tel.: + 38-096-203-58-53

E-mail:vzhyliuk@gmail.com

\begin{abstract}
Semenko, A. V., Murdasov, Y. V., Kirichenko, S. V., Zhyliuk, V. I., \& Ushakova, G. A. (2020). Influence of melatonin on the kidneys of rats with experimental diabetes mellitus type 2. Regulatory Mechanisms in Biosystems, $11(3), 384-391$. doi:10.15421/022059
\end{abstract}

Diabetes mellitus is characterized by numerous pathological changes in the body. Under conditions of diabetes, hyperglycemic intoxication of the organism rapidly develops, which in turn leads to an increase of oxidative stress with subsequent disturbance of the anatomical and functional integrity of the components of organisms. Today, the search for the substances that would contribute to the multi-vectoral effect on the negative consequences of diabetes is actively being pursued. Melatonin is one of such substances. In this work, we studied the effect of melatonin on oxidative stress markers (oxidized products content, activities of superoxide dismutase and catalase), the concentration of metabolism end products (creatinine and urea), main ions concentration (potassium and chlorine), and protein content (total protein and electropherogram in polyacrylamide gel), enzymatic activity of gamma-glutamyltrasferase in the cytosolic fraction of rat kidneys under condition of type 2 diabetes mellitus (EDM2). Experimental studies were performed on 18 white adult Wistar rats divided into three groups (control, group with EDM2 and group with EDM2, which were treated with melato$\mathrm{nin}$ ). The increase of concentration of oxidized products, the activity of catalase and gamma-glutamyltrasferase, creatinine, urea, $\mathrm{K}^{+}$ and $\mathrm{Cl}^{-}$and the decrease of concentration of superoxide dismutase in the rats' kidneys was noted after development of EDM2. The electrophoretic proteinogram of the cytosolic proteins obtained from the rats' kidneys showed an increase of content of highmolecular-weight and a decrease of low-molecular-weight proteins. Administration of melatonin in a dose of $10 \mathrm{mg} / \mathrm{kg}$ of body weight for 7 days after development of EDM2 restored the studied parameters almost to the control group values. Therefore, the influence of melatonin can prevent chronic development of oxidative stress in kidneys under hyperglycemic intoxication, and lead to normalization of kidney function and the restoration of homeostasis.

Keywords: hyperglycemia; oxidative stress; antioxidants; high-molecular-weight proteins; potassium;chlorine.

\section{Introduction}

Due to physiological conditions, glucose is completely reabsorbed from secondary urine in mammals. Under conditions of diabetes glucosuria occurs due to decreased level of proximal tubules' reabsorption of monosugars, which in turn leads to detection of glucose in the secondary urine (Vallon \& Thomson, 2017). At the same time, glucose itself and its underoxidized forms accumulate in the body, which in turn leads to an increase in the level of oxidative stress. The acute endotoxicity of the body occurs, which has a wide variety of consequences: changes in ion exchange, the development of anemia (Barbieri et al., 2015), cardiovascular diseases (Dludla et al., 2017; Lawson et al., 2018), renal failure (Michishita et al., 2017; Tonelli et al., 2019), thinning and fragility of bones (Valderrábano \& Linares, 2018).

The entire spectrum of renal impairment in diabetes is called diabetic nephropathy. Diabetic nephropathy occurs due to microstructural pathological changes in the structure of the renal glomeruli and renal tubules, generally leading to the synchronization of disturbed filtration and reabsorption processes. Such microstructural histological changes in the kidneys include hypertrophy of mesangial cells, hypertrophy of podocytes, hyalinization of arterioles, thickening of the basement membrane, atrophy of epithelial cells of the tubules of the kidneys, in some cases, albuminuria, inflammation. Transition to arteriolosclerosis and glomerulosclerosis is possible (Reidy et al., 2014). The main pathochemical mechanism of these processes is the cessation of utilization of glucose along the glycolysis pathway and its entrance to other metabolic pathways. Today, several biochemical mechanisms of pathogenesis in hyperglycemia are considered.
Activation of the polyol pathway is the result of hyperglycemic intoxication of the body. Glucose is converted to sorbitol by the action of the NADPH-dependent enzyme, then it is converted to fructose using NAD ${ }^{+}$. In this way, there is a decrease in the concentration of intracellular $\mathrm{NADPH}$, a cofactor involved in the formation of reduced glutathione, an antioxidant of cells. In addition, the conversion of sorbitol to fructose causes a redistribution of the $\mathrm{NADH} / \mathrm{NAD}^{+}$ratio, which in turn can lead to increased production of methylglyoxal and diacylglycerol, a precursor of the final glycation product and activator of protein kinase $\mathrm{C}$, respectively, which are also involved in the development of diabetic nephropathy and increased levels of oxidative damage (Yan, 2018). Moreover, according to an experimental model in mice with hyperglycemia, endogenous production of fructose from the polyol pathway led to an increase in proteinuria, a decrease in glomerular filtration, and an increase in damage to glomeruli and proximal tubules as compared to mice with lower levels of endogenous fructose. In addition, these mice had increased levels of oxidative stress of the kidneys and increased production of NF- $\mathrm{kB}$ (Lanaspa et al., 2014).

Activation of the hexazamine pathway leads to the formation of glucosamine-6-phosphate out of fructose-6-phosphate. The accumulation of glucosamine-6-phosphate and the high activity of fructose-6-phosphatamidotransferase activates the transcription of the inflammatory cytokine TNF- $\alpha$ and transforms the growth factor TGF- $\beta 1$. It is known that elevated levels of TGF- $\beta 1$ promote renal cell hypertrophy and increase the components of the mesangial matrix, while TNF- $\alpha$ (together with some other interleukins) increases vascular endothelial cell permeability, contributes to thickening of the glomerular basement membrane, and causes apoptosis (Schleicher \& Weigert, 2000). The end products of glycation are 
the result of irreversible glycation of proteins, occurs during hyperglycemic intoxication. There are three ways in which this process takes place: oxidation of glucose to glyoxal, degradation of Amadore products, and aberrant glycolysis, which promotes the formation of methyl glyoxal out of glyceraldehyde-3-phosphate (Rhee \& Kim, 2018). After formation, glycation end products damage cells by altering or impairing the function of both intracellular and extracellular proteins. For example, they modify both laminin and type IV collagen and, as shown, this leads to an increase in the permeability of the glomeruli of the basement membrane (Rodrigues et al., 2014).

The activation of the protein kinase $\mathrm{C}$ pathway through an increased diacylglycerol content leads to an increase in the level of prostaglandin $\mathrm{E}_{2}$ and nitric oxide activity, which in turn leads to vasodilation of the afferent arteriole and an increase in the effect of angiotensin II on the efferent arteriole; these actions together contribute to glomerular hyperfiltration. In the late stages of diabetic nephropathy, a state of progressive nitric oxide deficiency is observed, which is associated with severe proteinuria, decreased renal function, and hypertension (Toth-Manikowski \& Atta, 2015). When this pathway is activated, pathological changes in kidney podocytes occur (Teng et al., 2014).

Under conditions of the developed diabetes mellitus and diabetic nephropathy, the filtration ability of the kidneys decreases due to a violation of their microstructure, which is the cause of the accumulation of toxins in the body and, consequently, general endotoxication.

All the above changes in normal glucose metabolism, except pathological changes in the anatomically normal structure of the kidneys, lead to increased production of reactive oxygen species (ROS). The latter, in turn, plays an important role in kidney damage and lead to the development of diabetic nephropathy. The main consequence of the action of ROS on cells is a violation of the integrity of the membranes and, therefore, the impossibility of their normal functioning.

Recently, there has been an active search for substances that could help reduce oxidative stress and damage of cells, tissues and the body as a whole. One such substance is melatonin.

Melatonin (N-acetyl-5-methoxytryptamine) is a biochemically active substance with a wide spectrum of action on the human body; it is secreted mainly by the pineal gland, as well as by the retina, skin cells and in the digestive tract. It controls various physiological processes, including circadian rhythms, mood regulation, anxiety, sleep, appetite, immune responses and cardiac functions (Comai \& Gobbi, 2014).

Melatonin is characterized by an antioxidant property, is an activator of the production of its own antioxidants, and has anti-inflammatory, immunomodulatory, antitumour and antidiabetic effects. According to some studies, melatonin is a more active antioxidant than vitamins $\mathrm{C}$ and E, but in combination they can act synergistically (Meng et al., 2017).

The antioxidant properties of melatonin are provided by several routes of action of this substance. First, this is the direct interaction of melatonin with free radicals and substances that lead to oxidative damage. So, melatonin binds and deactivates carbonyl radicals, reactive oxygen species (hydroxyl radicals, superoxides, peroxides) and reactive nitrogen species (preventing the formation of a more dangerous compound like peroxynitrite). Interestingly, melatonin can catalyze one-electron transfer reactions, and protective compounds such as AFMK $\left(\mathrm{N}_{1}\right.$-acetyl- $\mathrm{N}_{2}$ formyl-5-methoxykinuramine) and AMK $\left(\mathrm{N}_{1}\right.$-acetyl-5-methoxykinuramine) are additionally formed from it (Galano et al., 2013; Galano et al., 2018).

Another way to protect cells from oxidative damage is the regulation of melatonin genes responsible for the synthesis of certain enzymes. Thus, it has been shown that melatonin activates the synthesis of antioxidant enzymes such as superoxide dismutase, catalase, and is involved in the metabolism of glutathione by regulating the corresponding glutathione enzymes. It can also suppress the expression of genes responsible for the synthesis of prooxidant enzymes: lipoxygenase and NO synthase (Hardeland, 2005).

In numerous studies under various conditions, the effectiveness of melatonin as an active antioxidant has been demonstrated. In our study, the main goal was to determine the effectiveness of melatonin on the state of the kidneys and their biochemical parameters in an experimental model on rats with streptozotocin-induced type 2 diabetes mellitus.

\section{Materials and methods}

Experimental studies were performed on 18 white sexually mature male rats of the Wistar strain weighing 230-250 g, which were divided into three groups $(\mathrm{n}=6)$ : group 1 - intact rats (control); group 2 - with experimentally reproduced streptozotocin-induced type 2 diabetes mellitus (EDM2); group 3 - EDM2 with melatonin administration.

The animals were kept on a standard diet while receiving food and drinking ad libitum in vivarium conditions at the state institution Dnipropetrovsk Medical Academy of the Ministry of Health of Ukraine (air temperature $-22 \pm 2{ }^{\circ} \mathrm{C}$, light / dark cycle $-12 / 12$ hours) in accordance with the sanitary hygiene standards. All experiments were carried out in accordance with the methods and requirements of the State Expert Center of the Ministry of Health of Ukraine, the rules of the "European Convention for the Protection of Vertebrate Animals which are used for experimental and other scientific purposes" (Strasbourg, 1986) and "Regulations on the use of animals in biomedical research".

To reproduce the experimental equivalent of type-2 diabetes, the animals, after preliminary 24-hour food deprivation (with preserved access to water), were once intraperitoneally injected with an aqueous solution of nicotinamide (Sigma-Aldrich, USA), $230 \mathrm{mg} / \mathrm{kg}$, and streptozotocin 15 minutes after that (Sigma-Aldrich, USA) at a dose of $65 \mathrm{mg} / \mathrm{kg}$ as a $5 \%$ solution in citrate buffer, $\mathrm{pH} 4.5$. Preliminary administration of nicotinamide increases the resistance of $\beta$-cells of islets of Langerhans from the cytotoxic effect of streptozotocin. Such a combination can reproduce a state close to type 2 diabetes mellitus, is manifested by moderate and stable hyperglycemia, impaired glucose tolerance, glucosuria without acidosis and weight gain. Blood glucose was determined 3 days after the reproduction of the pathology and 6-hour derivation of food with free access to water using an Optium Omega glucometer (Abbott Diabetes Care Inc., USA). For further studies, only animals with a high level of glucose $(8-14 \mathrm{mmol} / \mathrm{L})$ were used.

Melatonin (Vita-melatonin, JSC Kiev Vitamin Plant, Ukraine) was administered intragastrically once a day for the last 7 days of the experiment. The dose of the drug was $10 \mathrm{mg} / \mathrm{kg}$, which corresponds to the therapeutic range $\left(\mathrm{ED}_{50}\right)$, which is recommended in experimental studies in accordance with the recalculation formula. The control group of animals in the corresponding period of the experiment received water.

All measurements of biochemical parameters were carried out in the cytosolic protein fraction. To obtain cytosolic fractions, the kidneys were homogenized with glass in $0.1 \mathrm{M}$ Tris buffer, $\mathrm{pH} 7.4$ in a ratio of 1 to 10 . The homogenates were centrifuged for 1 hour at $20,000 \mathrm{~g}$ at $+4{ }^{\circ} \mathrm{C}$.

The measurement of the research parameters was carried out on a BS-3000M biochemical analyzer (SINNOWA Medical Science \& Technology Co., Ltd, China).

Three indicators were taken to assess the level of oxidative damage to the kidneys: the concentration of oxidized products in the reaction with thiobarbiturate acid, TBA-active compounds (Andreeva et al., 1988), the activity of superoxide dismutase (SOD) and catalase. SOD activity was measured by the oxidation reaction of quercetin (Kostuk et al., 1990); catalase activity was determined by the rate of decrease in $\mathrm{H}_{2} \mathrm{O}_{2}$ in the incubation medium (Koroluk et al., 1988).

The activity of gamma-glutamyltrasferase (GGT) and content of potassium and chlorine ions were measured using corresponding standard test kit (Felicity Diagnostics LLC, Ukraine).

Creatinine and urea - the final metabolic products are measured using the corresponding test kits (PZ Cormay S.A., Poland).

The total protein content in the cytosolic fraction obtained from rat kidneys was determined using the Bradford method (Bradford, 1985).

The polypeptide composition of proteins was studied with polyacrylamide gel electrophoresis (PAGE) in the presence of sodium dodecyl sulfate (SDS) (Laemmli, 1970). Two types of gel were used for electrophoresis: a concentrating gel containing acrylamide $-4.5 \%$, Tris $-0.125 \mathrm{M}$ (pH 6.8), SDS - 0.1\%, TEMED - $0.025 \%$, ammonium persulfate $0.025 \%$ and separating gel containing acrylamide $5.0-17.5 \%$, Tris $0.375 \mathrm{M}$ (pH 8.8), SDS - 0.1\%, TEMED - $0.025 \%$, ammonium persulfate $-0.025 \%$. Before electrophoresis, the studied proteins were dissolved in a working buffer, Tris $-0.0625 \mathrm{M}(\mathrm{pH} 6.8), \mathrm{SDS}-2 \%$, glycerol $10 \%$, dithiothreitol $-5 \%$, bromphenol blue $-0.001 \%$, and boiled in a 
water bath for 2 minutes. The composition of the electrode buffer included Tris $-0.025 \mathrm{M}(\mathrm{pH} 8.6)$, glycine $-0.192 \mathrm{M}$, SDS $-0.1 \%$. The total amount of protein per track did not exceed $20 \mu \mathrm{g}$. The concentration of proteins in the upper gel took place at a current of $12 \mathrm{~mA}$, the separation of polypeptides in the lower gel at $40 \mathrm{~mA}$.

The densitometry analysis of the proteinogram after PAGE was carried out with Core Laboratory Image Quantification 1D software (Cleaver Scientific Ltd, UK).

The values are presented as means (x) and standard deviation (SD). Statistical analysis was performed with two-way analysis of variance ANOVA and the Tukey post hoc test to assess the differences between experimental groups $(\mathrm{P}<0.05$ was considered to indicate statistical significance). Correlation of the studied parameters was calculated with Pearson's coefficient test.

\section{Results}

To study the kidney under hyperglycemic state the rats with developed experimentally streptozotocin-induced type 2 diabetes mellitus with 8-14 $\mathrm{mmol} / \mathrm{L}$ of glucose in the blood were used. The level of oxidized TBA-active compounds was increased by $106.3 \%(\mathrm{P}<0.05)$ in the kid- neys of rats with EDM2 compared to the control (Fig. 1). It was coincident with increased catalase activity by $147.1 \%(\mathrm{P}<0.05)$ in the kidneys of rats with EDM2 too. On the contrary, the activity of superoxide dismutase was decreased by $27.4 \%(\mathrm{P}<0.05)$ in the second group compared to the control.

The application with melatonin in a dose $10 \mathrm{mg} / \mathrm{kg}$ for the last 7 days of the experiment for rats with EDM2 led to decreased concentration by $34.5 \%$ of TBA-active compounds compared with the EDM2 group. The content of oxidized product in the kidneys was mostly close to the control value, however, it was not statistically different from EDM2 still. The activity of catalase decreased by $54.8 \%(\mathrm{P}<0.05)$ in the kidneys of rats that were injected with melatonin compared to rats that did not receive it. The activity of SOD in the kidneys of rats with application with melatonin was increased by $19.7 \%$ compared to the EDM2 group toward control value.

The same tendency was noted for the activity of gamma-glutamyltransferase in the cytosolic fraction obtained from the kidneys of rats under experiment (Fig. 2). The enzyme activity in the kidneys of rats with EDM2 increased by $60.4 \%$ relative to the control group. The level of GGT activity in rats treated with melatonin decreased by $27.7 \%$ compared with rats that did not receive the drug.
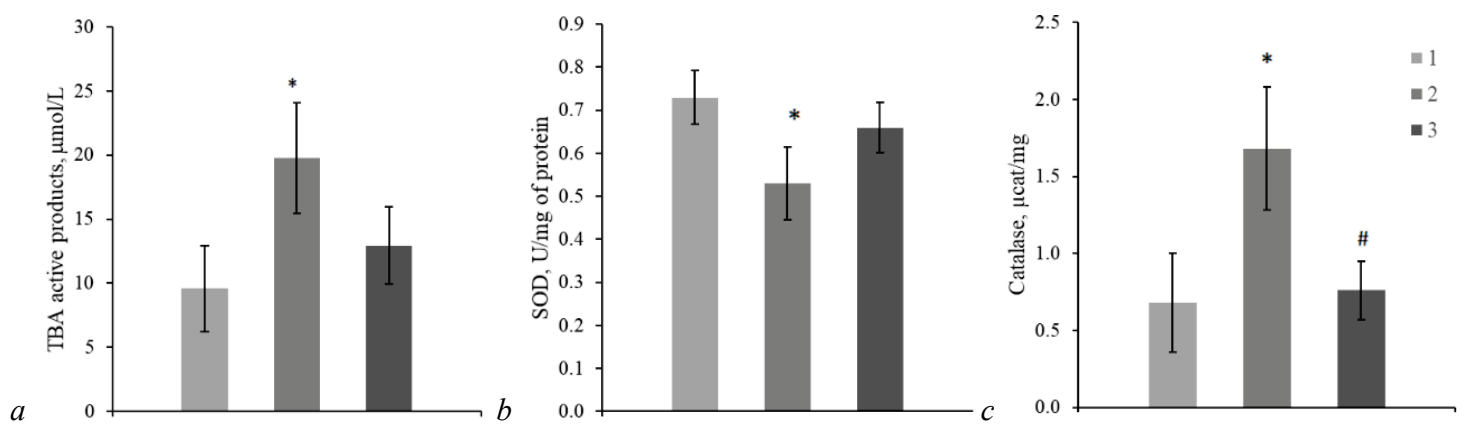

Fig. 1. The indicators of oxidative stress in the kidney of rats: the level of TBA active products $(a)$, activity of superoxide dismutase $(b)$ and catalase $(c)$ $(\mathrm{x} \pm \mathrm{SD}, \mathrm{n}=6): 1$ - animals of control group, 2 -animals with experimentally induced diabetes mellitus type 2,3 - animals with experimentally induced diabetes mellitus type 2 with melatonin application; * $-\mathrm{P}<0.05$ regarding control; ${ }^{*}-\mathrm{P}<0.05$ regarding EDM2

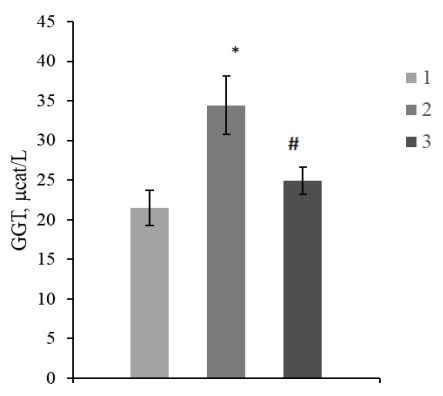

Fig. 2. The activity of gamma-glutamyltransferase in the kidneys of rats $(\mathrm{x} \pm \mathrm{SD}, \mathrm{n}=6): 1$ - animals of control group, 2 - animals with induced experimental diabetes mellitus type 2,3 - animals with induced experimental diabetes mellitus type 2 with melatonin application; $*_{-} \mathrm{P}<0.05$ regarding control; ${ }^{\#}-\mathrm{P}<0.05$ regarding EDM2

Induction of oxidative stress under development of experimental hyperglycemia led to elevation of end metabolic product in the kidney.

The concentration of creatinine and urea significantly increased in the kidneys of rats with EDM2 by $51.2 \%$ and $37.8 \%$, respectively compared to the control (Fig. 3). The administration of melatonin supported the normalization of studied parameters in the kidneys to normal values; however, the concentration of urea (Fig. 3b) was not statistically different from second group still. The development of EDM2 induced the changes of ion exchange of the kidneys of the studied rats. Thus, the concentration of potassium and chlorine ions in the kidneys of rats with EDM2 significantly increased in relation to the control by $58.1 \%$ and $57.3 \%$, respectively (Fig. 4). Under conditions of melatonin administration, the noted ion exchange indices decreased by $29.9 \%$ for potassium and by $31.2 \%$ for chlorine relative to the indicators of the second group.

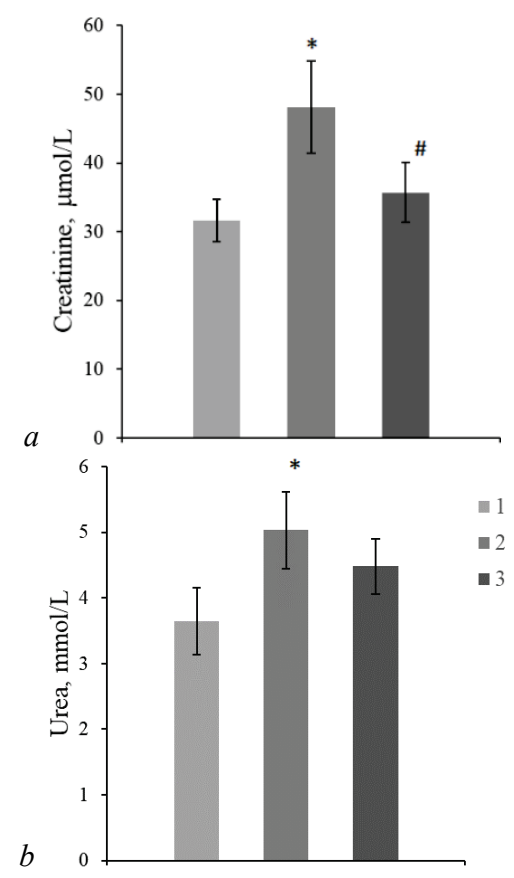

Fig. 3. The concentration of creatinine $(a)$ and urea $(b)$ in the cytosolic fraction obtained from the kidneys of rats $(\mathrm{x} \pm \mathrm{SD}, \mathrm{n}=6): 1$ - animals of control group; 2 -animals with induced experimental diabetes mellitus type 2;3-animals with induced experimental diabetes mellitus type 2 with melatonin application; * $-\mathrm{P}<0.05$ regarding control; ${ }^{\#}-\mathrm{P}<0.05$ regarding EDM2 
The development of type 2 diabetes mellitus in the rats led to anatomical rearrangements of the constituent of the kidneys to provoke the mass elevation by $57.1 \%(\mathrm{P}<0.05)$ regarding control animals (Fig. 5a). The increased mass of organ was coincident with increased concentration of total protein in the cytosolic fraction extracted from the kidneys of rats with EDM2 (Fig. 5b) to $9.6 \mathrm{mg}$ per $100 \mathrm{mg}$ tissue compared to $8.1 \mathrm{mg}$ per $100 \mathrm{mg}$ tissue of control rats (Fig. 2b). Supplementation with melatonin after development of EDM2 led to restoration of kidneys - both for mass and for level of total protein to control value. The changes of mass of rats' kidneys and total level of cytosolic protein had the positive Pearson correlation coefficient $r=0.99(\mathrm{P}<0.005)$.

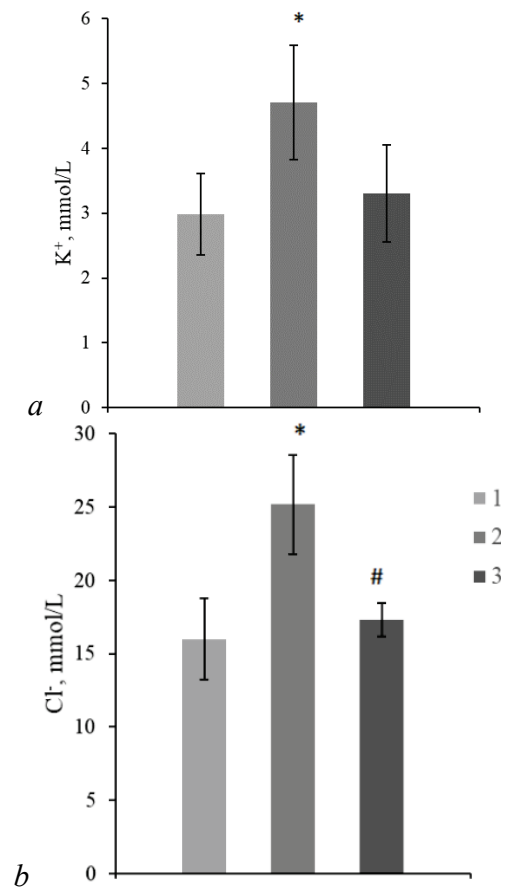

Fig. 4. The concentration of potassium $(a)$ and chlorine $(b)$ in the cytosolic fraction from the kidneys of rats $(\mathrm{x} \pm \mathrm{SD}, \mathrm{n}=6)$ : 1 -animals of control group, 2 - animals with induced experimental diabetes mellitus type 2,3-animals with induced experimental diabetes mellitus type 2 with melatonin application; ${ }^{*}-\mathrm{P}<0.05$ regarding control; ${ }^{\#}-\mathrm{P}<0.05$ regarding EDM2

The electrophoresis in the polyacrylamide gel of the cytosolic proteins extracted from the kidneys of the studied rats showed the quantitative changes in the ratio of proteins of different molecular weights. Most changes were representative for the five proteins with different molecular weights. The tendency to an increase the level of high molecular weight proteins and a decrease of low molecular weight proteins in the kidneys of rats with EDM2 relative to the control were registered (Fig. 6).

The content of proteins with molecular weights of 205, 162 and $48 \mathrm{kDa}$ increased by $119.0 \%, 45.1 \%$ and $24.3 \%$, respectively in the cytosolic fraction of kidneys of rats with EDM2 compared to the control (Fig. 6b). The content of proteins with molecular weights of 33 and $27 \mathrm{kDa}$ decreased by $25.5 \%$ and $7.3 \%$, respectively in the kidneys of rats with EDM2. The supplementation with melatonin returned the value of the volume of some proteins only in the case of proteins weighing 205, 48 and $33 \mathrm{kDa}$. In the case of protein with $162 \mathrm{kDa}$, its volume increased even with respect to the second group by $62.7 \%$, and the volume of a low molecular weight protein with $27 \mathrm{kDa}$ decreased more by $15.3 \%$ relative to the group with EDM2 (Fig. 6c).

\section{Discussion}

The development of experimental hyperglycemia like diabetes mellitus type 2 in the rat leads not only to the increase of oxidative stress and damage in the kidneys, but affects its functional state also, which is manifested in a change of ion exchange and content of end products of metabolism. The normal blood glucose level in rats is $3.95-6.20 \mathrm{mmol} / \mathrm{L}$
(Wang et al., 2010). Under conditions of 8-14 mmol/L of glucose, acute and chronic hyperglycemia developed in the blood can modulate development of oxidative stress in the cells and organs. One of the first components of a cell suffering under such conditions are lipids. Oxidative damage of lipids can lead to a violation of the integrity of cell membranes, which, in turn, causes a cascade of pathological changes in the cell and tissue. TBA-active compounds are the products of the oxidation of polyunsaturated fatty acids, as well as a fatty acid such as arachidonic. The increased concentration of oxidized products in the cells has a negative consequence of increased level of free peroxide radicals. Since TBAactive compounds can interact with free amino acids and functional groups of proteins, modifying them into physiologically irregular and nonfunctional forms, they, in turn, play a role in increasing oxidative stress also, which can lead to the induction of changes in the normal ratio of antioxidant enzymes of catalase and superoxide dismutase. Catalase is an antioxidant cell defense enzyme whose main function is the decomposition of hydrogen peroxide to water and molecular oxygen. Superoxide dismutase is another antioxidant enzyme that catalyzes the reaction of superoxide dismutation into oxygen and hydrogen peroxide.

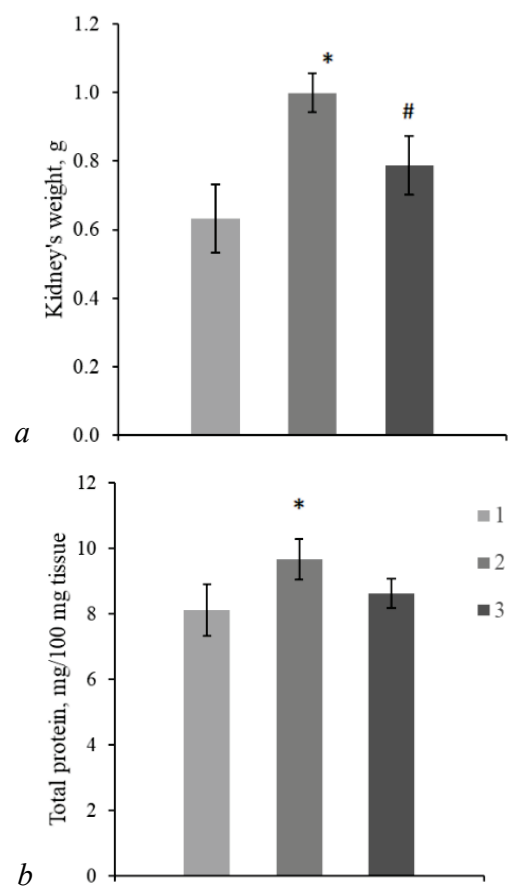

Fig. 5. The kidney's weight $(a)$ and total protein content in the cytosolic fraction obtained from the kidneys of rats $(b)(\mathrm{x} \pm \mathrm{SD}, \mathrm{n}=6)$ :

1 - animals of control group, 2 - animals with induced experimental diabetes mellitus type 2,3-animals with induced experimental diabetes mellitus type 2 with melatonin application;* $-\mathrm{P}<0.05$ regarding control;

$$
{ }^{\#}-\mathrm{P}<0.05 \text { regarding EDM2 }
$$

The development of hyperglycemic intoxication induced changes of concentration and activity of oxidative stress markers. Administration of melatonin in a dose $10 \mathrm{mg} / \mathrm{kg}$ for the last 7 days of the experiment for rats with EDM2 led to inhibition of oxidative stress and prevention of antioxidant system disturbance.

Previous studies demonstrated provocation of oxidative stress both in the homogenates of animal organs and in the blood plasma of people with different pathology. The administration of melatonin helped to normalize the concentration of malondialdehyde (MDA, the main TBA-active compound) in rats with streptozocin-induced diabetes even in experimental obesity, while L-carnitine and sugar-lowering drug glibenclamide showed worse results (Salmanoglu et al., 2016). The administration of vitamins E and $C$, as well as unsaturated fatty acids stabilized the level of MDA in the blood plasma of people with type 2 diabetes mellitus also (Mahmoudabadi \& Rahbar, 2014; Chatziralli et al., 2017). So, it can be assumed that the simultaneous administration of melatonin and antioxidant vitamins could lead to best result in the reduction of oxidative damage of cells and the oxidative modification of lipids. 

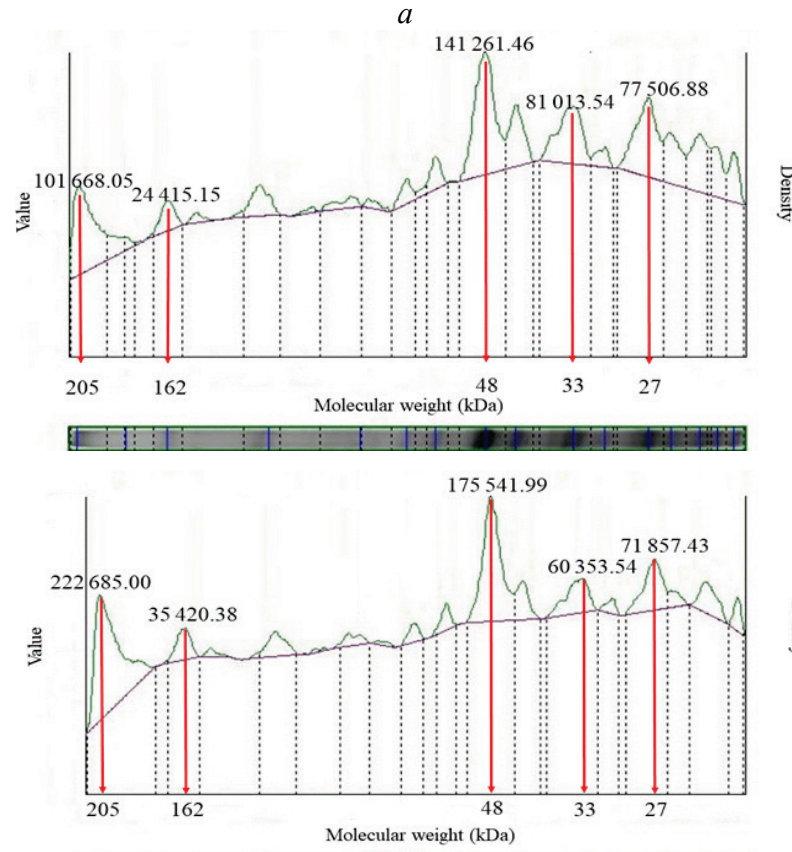

$b$

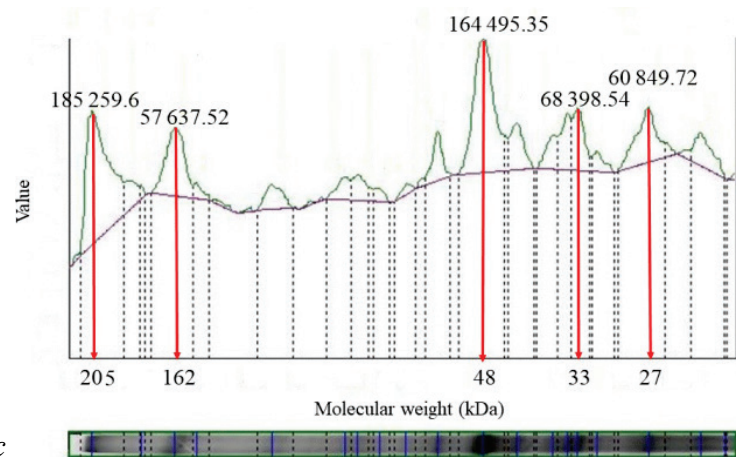

Fig. 6. The densitometry of proteinogram of the cytosolic fraction from the kidney of rats; the red arrows indicate most changed proteins with noted molecular weight (bottom) and altered value (top): $a$ - animals of control group, $b$-animals with induced experimental diabetes mellitus type 2,c-animals with induced experimental diabetes mellitus type 2 with melatonin application

In our work, the activity of superoxide dismutase enzyme in the kidneys of rats under EDM2 decreased and restored with the melatonin administration. Some studies report that a significant difference in the enzyme activity between the control group and the group with type 2 diabetes mellitus is absent in the kidneys (Chatuphonprasert et al., 2013). However, diabetic nephropathy and diabetes mellitus were studied in rats in which there was a noticeable decrease SOD activity compared to the control (Fujita et al., 2009; Jung et al., 2017). With the development of type 2 diabetes, the activity of SOD in the blood serum increases, which is logical, since the homeostatic mechanisms of the body try to maintain pro- and antioxidant balance (Bandeira et al., 2012). The decrease of SOD activity under EDM2 in the kidneys of rats may be a result connected with several isoforms of superoxide dismutase (Tangvarasittichai, 2015), each of which is active in a particular organ, tissue or part of the cell and, possibly, one of the SOD isoforms that is more characteristic for the kidneys which have succumbed to oxidative damage. Moreover, the intensive development of oxidative stress can lead to depletion of antioxidant potential in the kidneys.

The increased activity of catalase in the kidneys of rats with EDM2 was revealed in comparison with the control group, which indicates the activation of the compensatory mechanisms of the antioxidant defense of rats. Interestingly, the development of fluoride-induced oxidative stress in the kidneys that is not associated with diabetes mellitus also increases catalase levels compared to controls (Bharti et al., 2014) as in our study.
However, we can suggest that with a longer retention of experimental animals with subsequent intensification of pathological morphofunctional and biochemical changes under EDM2 the catalase defense system could be depleted, and the enzyme activity could decrease. Our assumption is based on the fact that globally most studies report specifically about a decrease of catalase activity in rat kidney homogenates compared with healthy individuals. Thus, in streptozocin-induced type 2 diabetes mellitus and alloxan-induced type 1 diabetes mellitus, catalase activity in rat kidneys decreases compared to the control (Ahmadvand et al., 2014; Gomathi et al., 2014).

The activity of gamma-glutamyltransferase increased in the kidneys of rats with EDM2 too. This enzyme is involved in the metabolism of glutathione (non-enzymatic antioxidant) and certain amino acids - it transfers the gamma-glutamyl group to peptides and amino acids. GGT is localized on the surface of the membrane and responsible for the metabolism of extracellular glutathione, promotes hydrolysis and facilitates its reuse for intracellular synthesis. Glutathione is a substrate of glutathione peroxidase and glutathione S-transferase, which play a key role in protecting against oxidative stress and detoxification/metabolism of endogenous and exogenous compounds, including carcinogens and drugs (Avelar et al., 2015). According to numerous studies, GGT is a predictor of many chronic diseases, including metabolic syndrome (Wei et al., 2015), insulin resistance (Ryoo et al., 2014), diabetes mellitus (Sabanayagam et al., 2009), and kidney disease (Torino et al., 2016). In addition, it can be assumed that the GGT and glutathione synthesis system is one of the first compensatory mechanisms with the beginning of the development of pathologies.

On the other hand, there is evidence about the role of GGT in the development of oxidative stress. So, under physiological conditions in the presence of iron ions or other transition metals and a large amount of thiolate, GGT can produce cystenylglycine, a product of the decomposition of glutathione. This dipeptide, reacting with iron ions, induces Fenton's reaction, followed by the formation of a superoxide radical.

The changes in the activity of antioxidant enzymes in the kidneys under conditions of hyperglycemic intoxication is one of the main predictors of the development of diabetic nephropathy. As already mentioned, today there is an active search for biologically active substances that could help reduce oxidative stress of organs and normalize work of the antioxidant system. In relation to the kidneys, the antioxidant properties of substances such as vitamins (C, D and E), coenzyme $\mathrm{Q}_{10}$, and flavanoids were studied (Mahmoodnia et al., 2017). Also, active antioxidant substances capable of lowering blood sugar levels such as resveratrol (Sadi et al., 2018), glibenclamide, humic acid and metformin, (Erejuwa et al., 2011; Salmanoglu et al., 2016) were investigated. Melatonin demonstrates high antioxidant properties and the ability to reduce the level of oxidative stress of organs and the body as a whole. Thus, it is reported to have a higher antioxidant property than quercetin (Rastogi \& Haldar, 2018), vitamin D (Alqasim et al., 2017), E (Montilla et al., 2001) and C (Khaldy et al., 2000). It is also valid that, in combination with other antioxidants, melatonin has a synergistic effect, which leads to a more intensive utilization of ROS and oxidative radicals, followed by a decrease in oxidative damage in the internal environment of the body.The administration of melatonin after development of EDM2 induced the significant decrease of both catalase and gamma-glutamyltransferase activity and content of oxidized products in the kidneys of rats towards normal value, which may be associated with the neutralization of $\mathrm{H}_{2} \mathrm{O}_{2}$ by melatonin itself, which is known for its antioxidant properties.

The activation of oxidative stress under hyperglycemic condition led to significant increase of urea and creatinine (the nitrogen included final products of metabolism) concentration in the rat kidneys compared with the control. As other studies have shown, under streptozotocin-induced type 1 and type 2 diabetes mellitus, the increase of creatinine and urea in the blood serum of the studied animals was observed (Moridi et al., 2015; Ghasemi et al., 2019), which correlates with our data. Moreover, these parameters in humans with diabetes may increase in the blood serum, while urine urea and creatinine levels decrease during the development of diabetes and its complications (Bispo et al., 2013). The level of the mentioned endmetabolism compounds can be used to assess the functional activity of the kidneys and the degree of their efficiency. Under conditions of hyperglycemia, the filtration apparatus of the kidneys is damaged and the dri- 
ving forces - osmotic and oncotic pressures, which are the basis for filtration, change. The mechanism of such functional changes in the kidneys is associated with a violation of the filtration ability of the glomeruli due to its pathomorphological transformations and a change in the work of the corresponding transporters in connection with a violation of the integrity of the membranes of the kidney cells. Angiotensin-II, adiponectin and leptin can also play a role in the transformation of kidney structures. Urea and creatinine are filtered in the glomeruli of the kidneys. It is known that hyperglycemia, high blood pressure and oxidative stress can cause glomerular hyperfiltration. Under such conditions, a pathological transformation of the mesangium of the nephrons and basement membranes can be induced. Negative charge losses can be also observed, which leads to increased permeability of proteins and low molecular weight substances. Longterm hyperfiltration causes the deposition of proteins, albumin, end products of metabolism in the mesangium, and provokes its expansion and proliferation. Subsequently, pathomorphological changes in the mesangium and basement membrane lead to glomerulosclerosis and hyalinosis of arterioles. Also, as discussed in the introduction, oxidative stress affects microstructural changes in the kidneys and glucose begins to be metabolized in other pathways. Under such conditions, the urea transporters (UT-A family) disrupt its reabsorption (proximal tubule, collection tubes) and secretion (Henle loop) (Klein et al., 2012), and the urea transporter (OCT1/2) is disrupted (Ciarimboli et al., 2012), which secretes it into the proximal tubule.

It is known that under conditions of hyperglycemic intoxication, an increase in the activity of the renin-angiotensin-aldosterone system (RAAS) occurs, which, in turn, leads to an increased level of circulating angiotensin-II and aldosterone (Nishiyama \& Kobori, 2018). In turn, aldosterone affects the excretion of potassium in the tubules of the kidneys - with increased aldosterone, potassium losses occur with the subsequent development of hypokalemia. These data were confirmed using RAAS blockers for patients with diabetes mellitus (Weir \& Rolfe, 2010). At the same time, aldosterone affects the increase in chlorine reabsorption in the tubules of the kidneys. There is evidence that activation of RAAS is one of the causes of the development of renal failure and microstructural changes in the kidneys (Chen et al., 2018).

Hyperglycemia and its most varied consequences, such as changes in the normal functioning of cell membranes, hyperfiltration can lead to changes in ion exchange in the processes of filtration and reabsorption. Due to ion exchange disorder, hyperosmolarity of the fluid or intracellular environment may occur. The transport of potassium and chlorine ions is important for the whole body, as they also participate in the transport of sodium and certain substances. The levels of potassium and chlorine ions in the rat kidneys was significantly increased under EDM2 compared with the control group. But, according to the first assumption, from which a close relationship of hyperglycemia and activation of RAAS can be traced, an increase in the levels of both ions is impossible. The explanation for this is the destruction due to oxidative stress, high blood pressure and inflammation of the juxtamedular apparatus of the nephrons - the main place of renin synthesis. Renin is an enzyme, one of the main components of RAAS. A decrease in renin synthesis leads to a state of hyporenin hypoaldosteronism, which explains hyperkalemia in patients with diabetes mellitus. Due to decrease in potassium secretion (and, as a result, chronic hyperglycemia), the excretion of $\mathrm{NH}_{4}^{+}$ions in the collecting tubes of the kidneys is impaired. This leads to metabolic acidosis, the most frequent manifestation of which is hyperchloremic metabolic acidosis due to insufficient secretion of $\mathrm{K}^{+}$and $\mathrm{H}^{+}$(Sousa et al., 2016). Thus, in the kidneys of rats with EDM2, hyperkalemia and hyperchloremia simultaneously may be developed.

The induction of oxidative stress and intoxication in the kidneys of rats with EDM2 triggered the increase of total protein content in the kidneys and their mass compared with control animals. There are several explanations for this process. First of all, this happens due to the accumulation of cytokines and growth factors, such as IL-1, IL-6, IL-18, NF-kB and TNF- $\alpha$, which subsequently lead to inflammatory processes (García-García et al., 2014). The phenomenon of apoptosis and necrosis, in turn, also leads to the accumulation of proteins, while under the influence of growth factors TGF- $\beta$ and VEGF, hypertrophy of the constituent of the kidneys and the organ as a whole occurs (Mahmoodnia et al., 2017). It can be assumed that the activity of macrophages under the conditions of development of EDM2 is reduced, and therefore unnecessary proteins and their residues are not disposed of, as the level of filtering ability of the kidneys is also reduced. Pathological morphofunctional changes in the kidneys are caused by the oxidative modification of structural proteins with their subsequent decomposition, that can affect the throughput of the glomeruli with the development of pathological conditions such as microand macroalbuminaria-registration of low and high molecular weight proteins in the urine. Pearson's correlation coefficient $(\mathrm{r}=0.99, \mathrm{P}<0.005)$ showed a close relationship between the increase of total protein content and kidney mass. The occurrence of these phenomena in the kidneys of rats is due to hyperglycemic intoxication, because, as mentioned earlier, glucose is metabolized not by the glycolysis path, but by other pathways, the result of which is activation and accumulation of reactive oxygen species, toxic intermediates and signaling substances.

Under development of experimental type 2 diabetes mellitus in the kidneys of rats, the number of high-molecular-weight proteins was increased, while that of low-molecular-weight proteins was decreased. It can be explained by aggregation of protein due to oxidative modification. Oxidative stress is one of the main causes of the formation of beta-amyloid plaques, the accumulation of which leads to the development of neurodegenerative, cardiovascular and other diseases (Squier, 2001), since the accumulation of aggregated proteins leads to a change in cell functions and their death, therefore it is possible that this process is also involved in the pathogenesis of kidneys after development of EDM2. The intensification of the formation of protein aggregates is also influenced by inflammatory processes and the redistribution of ionic composition. Additionally, the development of microalbuminuria in rats with diabetic nephropathy can affect the change in the ratio of proteins by molecular weight. At the same time, it has been reported that protein aggregation can serve as a protective response to the active production of reactive oxygen species (ROS) (Carija et al., 2017), in order to avoid the excessive generation of ROS (Vasconcellos et al., 2016) and as one of the signaling mechanisms of cells to prevent the induction of apoptosis under conditions of stress (Wall, 2012; Cai \& Yan, 2013).

The normalization of filtration and ion change, the total protein content and kidney mass after development of EDM2 can be influenced by such properties of melatonin as antioxidant ones and anti-inflammatory and immune-stimulating. It is known that melatonin can inhibit the expression of NF- $\kappa \mathrm{B}$, cytokines/chemokines inflammation, affect the synthesis of TNF- $\alpha$, IL-1, IL-6 (Meng et al., 2017). However, the changes of proteins with 162 and $27 \mathrm{kDa}$ under supplementation of melatonin are quite unpredictable and require more detailed study.

Melatonin may prevent the further development of pathomorphological microstructural changes in nephrons, reduce the level of ROS and cytokines in the internal environment of kidney cells, normalizing the clearance of creatinine and urea, helping to reduce the level of oxidative damage to the juxtamedicular apparatus and normalizing the RAA system. Moreover, melatonin and its metabolites have anti-diabetic properties. The presence of melatonin receptors in the pancreas suggests that their activation by melatonin can directly affect the production of insulin or glucagon. The decreased level of melatonin in patients with diabetes can affect pancreatic function, and administration of melatonin induce the decrease of glucose concentration in blood (Karamitri et al., 2013). Melatonin has been shown to improve dysglycemia in rats by inhibiting liver gluconeogenesis and activation of hypothalamic akt through membrane receptors MT1 and MT2 (Faria et al., 2013). Previously it was shown that pharmacological doses of melatonin increased $\mathrm{Ca}^{2+}$ levels in many organs and tissues, resulting in improved insulin sensitivity, suggesting the potential clinical use of melatonin against type 2 diabetes (Agil et al., 2015). In addition, melatonin can prevent the degradation of pancreatic islets caused by the loss of beta cells and their dysfunction in type 2 diabetes mellitus, weakening apoptosis and improving their function through activation of melatonin signaling (Costes et al., 2015).

\section{Conclusions}

Chronic hyperglycemia provokes development of oxidative stress and accumulation of aggregated proteins in the kidneys of rats thus redu- 
cing the main function. Application of melatonin in a dose $10 \mathrm{mg} / \mathrm{kg}$ body weight for 7 days after formation of stable hyperglycemia prevents further development of oxidative stress and modulates normalization of creatinine and urea clearance, thereby stabilizing the total protein content and the ratio of high- and low-molecular proteins in the kidneys.

This work was supported by the Ministry of Education and Science of Ukraine (0118U003301).

\section{References}

Agil, A., Elmahallawy, E. K., Rodríguez-Ferrer, J. M., Adem, A., Bastaki, S. M., AlAbbadi, I., Fino Solano, Y. A., \& Navarro-Alarcón, M. (2015). Melatonin increases intracellular calcium in the liver, muscle, white adipose tissues and pancreas of diabetic obese rats. Food and Function, 6(8), 2671-2678.

Ahmadvand, H., Ghasemi Dehnoo, M., Cheraghi, R., Rasoulian, B., Ezatpour, B., Azadpour, M., \& Baharvand, K. (2014). Amelioration of altered serum, liver, and kidney antioxidant enzymes activities by sodium selenite in alloxaninduced diabetic rats. Reports of Biochemistry and Molecular Biology, 3(1), 14-20.

Alqasim, A. A., Noureldin, E., Hammadi, S. H., \& Esheba, G. E. (2017). Effect of melatonin versus vitamin D as antioxidant and Hepatoprotective agents in STZinduced diabetic rats. Journal of Diabetes and Metabolic Disorders, 16, 41.

Andreeva, L. Y., Kozhemiakyn, L. A., \& Kyshkun, A. A. (1988). Modyfykacyja metoda opredelenyja perekysej lypydov v teste s tyobarbyturovoj kyslotoj [Modification of the method of determining lipid peroxidation in a test using thiobarbituric acid]. Laboratornoe Delo, 11, 41-43 (in Russian).

Avelar, T. M. T., Storch, A. S., Castro, L. A., Azevedo, G. V. M. M., Ferraz, L., \& Lopes, P. F. (2015). Oxidative stress in the pathophysiology of metabolic syndrome: Which mechanisms are involved? Jornal Brasileiro de Patologia e Medicina Laboratorial, 51(4), 231-239.

Bandeira, S., Guedes, G., da Fonseca, L. J., Pires, A. S., Gelain, D. P., Moreira, J. C., Rabelo, L. A., Vasconcelos, S. M. L., \& Goulart, M. O. (2012). Characterization of blood oxidative stress in type 2 diabetes mellitus patients: Increase in lipid peroxidation and SOD activity. Oxidative Medicine and Cellular Longevity, 2012, 819310.

Barbieri, J., Fontela, P. C., Winkelmann, E. R., Zimmermann, C. E., Sandri, Y. P., Mallet, E. K., \& Frizzo, M. N. (2015). Anemia in patients with type 2 diabetes mellitus. Anemia, 2015, 354737.

Bharti, V. K., Srivastava, R. S., Kumar, H., Bag, S., Majumdar, A. C., Singh, G., PandiPerumal, S. R., \& Brown, G. M. (2014). Effects of melatonin and epiphyseal proteins on fluoride-induced adverse changes in antioxidant status of heart, liver, and kidney of rats. Advances in Pharmacological Sciences, 2014, 532969.

Bispo, J. A., de Sousa Vieira, E. E., Silveira Jr., L., \& Fernandes, A. B. (2013). Correlating the amount of urea, creatinine, and glucose in urine from patients with diabetes mellitus and hypertension with the risk of developing renal lesions by means of Raman spectroscopy and principal component analysis. Journal of Biomedical Optics, 18(8), 87004.

Bradford, M. (1985). Rapid and sensitive methods for the quantitation of microgram quantities of protein utilizing the principle of protein-dye binding. Analytical Biochemistry, 72, 248-254.

Cai, Z., \& Yan, L. J. (2013). Protein oxidative modifications: beneficial roles in disease and health. Journal of Biochemical and Pharmacological Research, 1(1), 15-26.

Carija, A., Navarro, S., de Groot, N. S., \& Ventura, S. (2017). Protein aggregation into insoluble deposits protects from oxidative stress. Redox Biology, 12, 699-711.

Chatuphonprasert, W., Lao-Ong, T., \& Jarukamjorn, K. (2014). Improvement of superoxide dismutase and catalase in streptozotocin-nicotinamide-induced type 2 diabetes in mice by berberine and glibenclamide. Pharmaceutical Biology, 52(4), 419-427.

Chatziralli, I. P., Theodossiadis, G., Dimitriadis, P., Charalambidis, M., Agorastos, A., Migkos, Z., Platogiannis, N., Moschos, M. M., Theodossiadis, P., \& Keryttopoulos, P. (2017). The effect of vitamin E on oxidative stress indicated by serum malondialdehyde in insulin-dependent type 2 diabetes mellitus patients with retinopathy. The Open Ophthalmology Journal, 11, 51-58.

Chen, C. M., Juan, S. H., \& Chou, H. C. (2018). Hyperglycemia activates the reninangiotensin system and induces epithelial-mesenchymal transition in streptozotocin-induced diabetic kidneys. Journal of the Renin-Angiotensin-Aldosterone System, 19(3), 1470320318803009.

Ciarimboli, G., Lancaster, C. S., Schlatter, E., Franke, R. M., Sprowl, J. A., Pavenstädt, H., Massmann, V., Guckel, D., Mathijssen, R. H. J., Yang, W., Pui, C.-H., Relling, M. V., Herrmann, E., \& Sparreboom, A. (2012). Proximal tubular secretion of creatinine by organic cation transporter OCT2 in cancer patients. Clinical Cancer Research, 18(4), 1101-1108.
Comai, S., \& Gobbi, G. (2014). Unveiling the role of melatonin MT2 receptors in sleep, anxiety and other neuropsychiatric diseases: a novel target in psychopharmacology. Joumal of Psychiatry and Neuroscience, 39(1), 6-21.

Costes, S., Boss, M., Thomas, A. P., \& Matveyenko, A. V. (2015). Activation of melatonin signaling promotes $\beta$-cell survival and function. Molecular Endocrinology, 29(5), 682-692.

Dludla, P. V., Joubert, E., Muller, C., Louw, J., \& Johnson, R. (2017). Hyperglycemia-induced oxidative stress and heart disease-cardioprotective effects of rooibos flavonoids and phenylpyruvic acid-2-O- $\beta$-D-glucoside. Nutrition and Metabolism, 14, 45.

Erejuwa, O. O., Sulaiman, S. A., Wahab, M. S., Salam, S. K., Salleh, M. S., \& Gurtu, S. (2011). Comparison of antioxidant effects of honey, glibenclamide, metfor$\mathrm{min}$, and their combinations in the kidneys of streptozotocin-induced diabetic rats. International Joumal of Molecular Sciences, 12(1), 829-843.

Faria, J. A., Kinote, A., Ignacio-Souza, L. M., de Araújo, T. M., Razolli, D. S., Doneda, D. L., Paschoal, L. B., Lellis-Santos, C., Bertolini, G. L., Velloso, L. A., Bordin, S., \& Anhê, G. F. (2013). Melatonin acts through MT1/MT2 receptors to activate hypothalamic akt and suppress hepatic gluconeogenesis in rats. American Joumal of Physiology, Endocrinology and Metabolism, 305(2), e230-e242.

Fujita, H., Fujishima, H., Chida, S., Takahashi, K., Qi, Z., Kanetsuna, Y., Breyer, M. D., Harris, R. C., Yamada, Y., \& Takahashi, T. (2009). Reduction of renal superoxide dismutase in progressive diabetic nephropathy. Journal of the American Society of Nephrology, 20(6), 1303-1313.

Galano, A., Tan, D. X., \& Reiter, R. J. (2013). On the free radical scavenging activities of melatonin's metabolites, AFMK and AMK. Journal of Pineal Research, 54(3), 245-257.

Galano, A., Tan, D. X., \& Reiter, R. J. (2018). Melatonin: A versatile protector against oxidative DNA damage. Molecules, 23(3), 530.

García-García, P. M., Getino-Melián, M. A., Domínguez-Pimentel, V., \& NavarroGonzález, J. F. (2014). Inflammation in diabetic kidney disease. World Journal of Diabetes, 5(4), 431-443.

Ghasemi, H., Einollahi, B., Kheiripour, N., Hosseini-Zijoud, S. R., \& Farhadian Nezhad, M. (2019). Protective effects of curcumin on diabetic nephropathy via attenuation of kidney injury molecule 1 (KIM-1) and neutrophil gelatinaseassociated lipocalin (NGAL) expression and alleviation of oxidative stress in rats with type 1 diabetes. Iranian Joumal of Basic Medical Sciences, 22(4), 376-383.

Gomathi, D., Kalaiselvi, M., Ravikumar, G., Devaki, K., \& Uma, C. (2014). Evaluation of antioxidants in the kidney of streptozotocin induced diabetic rats. Indian Journal of Clinical Biochemistry, 29(2), 221-226.

Hardeland, R. (2005). Antioxidative protection by melatonin: Multiplicity of mechanisms from radical detoxification to radical avoidance. Endocrine, 27(2), 119-130.

Jung, H., Kim, Y. Y., Kim, B., Nam, H., \& Suh, J. G. (2017). Improving glycemic control in model mice with type 2 diabetes by increasing superoxide dismutase (SOD) activity using silk fibroin hydrolysate (SFH). Biochemical and Biophysical Research Communications, 493(1), 115-119.

Karamitri, A., Renault, N., Clement, N., Guillaume, J. L., \& Jockers, R. (2013). Minireview: Toward the establishment of a link between melatonin and glucose homeostasis: Association of melatonin MT2 receptor variants with type 2 diabetes. Molecular Endocrinology, 27(8), 1217-1233.

Khaldy, H., Escames, G., León, J., Vives, F., Luna, J. D., \& Acuña-Castroviejo, D. (2000). Comparative effects of melatonin, L-deprenyl, Trolox and ascorbate in the suppression of hydroxyl radical formation during dopamine autoxidation in vitro. Journal of Pineal Research, 29(2), 100-107.

Klein, J. D., Blount, M. A., \& Sands, J. M. (2012). Molecular mechanisms of urea transport in health and disease. Pflugers Archiv - European Journal of Physiology, 464(6), 561-572.

Koroljuk, M. A., Yvanova, L. Y., Majorova, Y. G., \& Tokareva, V. E. (1988). Metod opredelenyja aktyvnosty katalazy [Method for the determination of catalase activity]. Laboratornoe Delo, 1, 16-19 (in Russian).

Kostjuk, V. A., Potapovych, A. Y., \& Kovaleva, Z. V. (1990). Prostoj i chuvstvitel'nyj metod opredelenija aktivnosti uperoksiddismutazy, osnovannyj na reakcii okislenija kvercetina [A simple and sensitive method for determining the activity of superoxide dismutase, based on the oxidation reaction of quercetin]. Questions of Medical Chemistry, 36, 2, 88-91 (in Russian).

Laemmli, U. K. (1970). Cleavage of structural proteins during the assembly of the head of bacteriophage T4. Nature, 227, 680-685.

Lanaspa, M. A., Ishimoto, T., Cicerchi, C., Tamura, Y., Roncal-Jimenez, C. A., Chen, W., Tanabe, K., Andres-Hernando, A., Orlicky, D. J., Finol, E., Inaba, S., Li, N., Rivard, C. J., Kosugi, T., Sanchez-Lozada, L. G., Petrash, M., Sautin, Y. Y., Ejaz, A. A., Kitagawa, W., Garcia, G. E., Bonthron, D. T., Asipu, A., Diggle, C. P., Rodriguez-Iturbe, B., Nakagawa, T., \& Johnson, R. J. (2014). Endogenous fructose production and fructokinase activation mediate renal injury in diabetic nephropathy. Journal of the American Society of Nephrology, 25(11), 2526-2538.

Lawson, T. B., Scott-Drechsel, D. E., Chivukula, V. K., Rugonyi, S., Thomburg, K. L., \& Hinds, M. T. (2018). Hyperglycemia alters the structure and hemody- 
namics of the developing embryonic heart. Journal of Cardiovascular Development and Disease, 5(1), 13.

Mahmoodnia, L., Aghadavod, E., Beigrezaei, S., \& Rafieian-Kopaei, M. (2017). An update on diabetic kidney disease, oxidative stress and antioxidant agents. Journal of Renal Injury Prevention, 6(2), 153-157.

Mahmoudabadi, M. M., \& Rahbar, A. R. (2014). Effect of EPA and vitamin C on superoxide dismutase, glutathione peroxidase, total antioxidant capacity and malondialdehyde in type 2 diabetic patients. Oman Medical Journal, 29(1), 39-45.

Meng, X., Li, Y., Li, S., Zhou, Y., Gan, R. Y., Xu, D. P., \& Li, H. B. (2017). Dietary sources and bioactivities of melatonin. Nutrients, 9(4), 367.

Michishita, R., Matsuda, T., Kawakami, S., Tanaka, S., Kiyonaga, A., Tanaka, H., Morito, N., \& Higaki, Y. (2017). Hypertension and hyperglycemia and the combination thereof enhances the incidence of chronic kidney disease (CKD) in middle-aged and older males. Clinical and Experimental Hypertension, 39(7), 645-654.

Montilla, P., Cruz, A., Padillo, F. J., Túnez, I., Gascon, F., Muñoz, M. C., Gómez, M., \& Pera, C. (2001). Melatonin versus vitamin E as protective treatment against oxidative stress after extra-hepatic bile duct ligation in rats. Journal of Pineal Research, 31(2), 138-144.

Moridi, H., Karimi, J., Sheikh, N., Goodarzi, M. T., Saidijam, M., Yadegarazari, R., Khazaei, M., Khodadadi, I., Tavilani, H., Piri, H., Asadi, S., Zarei, S., \& Rezaei, A. (2015). Resveratrol-dependent down-regulation of receptor for advanced glycation end-products and oxidative stress in kidney of rats with diabetes. International Journal of Endocrinology and Metabolism, 13(2), e23542.

Nishiyama, A., \& Kobori, H. (2018). Independent regulation of renin-angiotensinaldosterone system in the kidney. Clinical and Experimental Nephrology, 22(6), 1231-1239.

Rastogi, S., \& Haldar, C. (2018). Comparative effect of melatonin and quercetin in counteracting LPS induced oxidative stress in bone marrow mononuclear cells and spleen of Funambulus pennanti. Food and Chemical Toxicology, 120, 243-252.

Reidy, K., Kang, H. M., Hostetter, T., \& Susztak, K. (2014). Molecular mechanisms of diabetic kidney disease. The Journal of Clinical Investigation, 124(6), 2333-2340.

Rhee, S. Y., \& Kim, Y. S. (2018). The role of advanced glycation end products in diabetic vascular complications. Diabetes and Metabolism Journal, 42(3), 188-195.

Rodrigues, L., Matafome, P., Crisóstomo, J., Santos-Silva, D., Sena, C., Pereira, P., \& Seiça, R. (2014). Advanced glycation end products and diabetic nephropathy: A comparative study using diabetic and normal rats with methylglyoxal-induced glycation. Journal of Physiology and Biochemistry, 70(1), 173-184.

Ryoo, J. H., Oh, C. M., Kim, H. S., Park, S. K., \& Choi, J. M. (2014). Clinical association between serum $\gamma$-glutamyltransferase levels and the development of insulin resistance in Korean men: A 5-year follow-up study. Diabetic Medicine, 31(4), 455-461.

Sabanayagam, C., Shankar, A., Li, J., Pollard, C., \& Ducatman, A. (2009). Serum gamma-glutamyl transferase level and diabetes mellitus among US adults. European Journal of Epidemiology, 24(7), 369-373.

Sadi, G., Şahin, G., \& Bostanc1, A. (2018). Modulation of renal insulin signaling pathway and antioxidant enzymes with streptozotocin-induced diabetes: Effects of resveratrol. Medicina, 55(1), e3.
Salmanoglu, D. S., Gurpinar, T., Vural, K., Ekerbicer, N., Dariverenli, E., \& Var, A. (2016). Melatonin and L-camitin improves endothelial disfunction and oxidative stress in Type 2 diabetic rats. Redox Biology, 8, 199-204.

Schleicher, E. D., \& Weigert, C. (2000). Role of the hexosamine biosynthetic pathway in diabetic nephropathy. Kidney International, Supplement, 77, S13-S18.

Sousa, A. G., Cabral, J. V., El-Feghaly, W. B., de Sousa, L. S., \& Nunes, A. B. (2016) Hyporeninemic hypoaldosteronism and diabetes mellitus: Pathophysiology assumptions, clinical aspects and implications for management. World Journal of Diabetes, 7(5), 101-111.

Squier, T. C. (2001). Oxidative stress and protein aggregation during biological aging. Experimental Gerontology, 36(9), 1539-1550.

Tangvarasittichai, S. (2015). Oxidative stress, insulin resistance, dyslipidemia and type 2 diabetes mellitus. World Journal of Diabetes, 6(3), 456-480.

Teng, B., Duong, M., Tossidou, I., Yu, X., \& Schiffer, M. (2014). Role of protein kinase $\mathrm{C}$ in podocytes and development of glomerular damage in diabetic nephropathy. Frontiers in Endocrinology, 5, 179.

Tonelli, M., Wiebe, N., Richard, J. F., Klarenbach, S. W., \& Hemmelgarn, B. R. (2019). Characteristics of adults with type 2 diabetes mellitus by category of chronic kidney disease and presence of cardiovascular disease in Alberta Canada: A cross-sectional study. Canadian Journal of Kidney Health and Disease, 6, 1-13.

Torino, C., Mattace-Raso, F., van Saase, J. L., Postorino, M., Tripepi, G. L., Mallamaci, F., Zoccali C., \& Progredire Study Group (2016). Oxidative stress as estimated by gamma-glutamyl transferase levels amplifies the alkaline phosphatase-dependent risk for mortality in ESKD patients on dialysis. Oxidative Medicine and Cellular Longevity, 2016, 8490643.

Toth-Manikowski, S., \& Atta, M. G. (2015). Diabetic kidney disease: Pathophysiology and therapeutic targets. Journal of Diabetes Research, 2015, 697010.

Valderrábano, R. J., \& Linares, M. I. (2018). Diabetes mellitus and bone health: Epidemiology, etiology and implications for fracture risk stratification. Clinical Diabetes and Endocrinology, 4, 9.

Vallon, V., \& Thomson, S. C. (2017). Targeting renal glucose reabsorption to treat hyperglycaemia: The pleiotropic effects of SGLT2 inhibition. Diabetologia, 60(2), 215-225.

Vasconcellos, L. R., Dutra, F. F., Siqueira, M. S., Paula-Neto, H. A., Dahan, J., Kiarely, E., Carneiro, L. A. M., Bozza, M. T., \& Travassos, L. H. (2016). Protein aggregation as a cellular response to oxidative stress induced by heme and iron. Proceedings of the National Academy of Sciences of the United States of America, 113(47), e7474 e7482.

Wall, S. B., Oh, J. Y., Diers, A. R., \& Landar, A. (2012). Oxidative modification of proteins: An emerging mechanism of cell signaling. Frontiers in Physiology, 3, 369.

Wang, Z., Yang, Y., Xiang, X., Zhu, Y., Men, J., \& He, M. (2010). Estimation of the normal range of blood glucose in rats. Journal of Hygiene Research, (39)2, 133-137.

Wei, D., Chen, T., Li, J., Gao, Y., Ren, Y., Zhang, X., Yu, H., \& Tian, H. (2015). Association of serum gamma-glutamyl transferase and ferritin with the metabolic syndrome. Journal of Diabetes Research, 2015, 741731.

Weir, M. R., \& Rolfe, M. (2010). Potassium homeostasis and renin-angiotensinaldosterone system inhibitors. Clinical Journal of the American Society of Nephrology, 5(3), 531-548.

Yan, L. J. (2018). Redox imbalance stress in diabetes mellitus: Role of the polyol pathway. Animal Models and Experimental Medicine, 1(1), 7-13. 